\title{
A Comparison of the Behavior of Single Crystalline and Nanowire Array ZnO Photoanodes
}

\author{
Anthony Fitch, Nicholas C. Strandwitz, Bruce S. Brunschwig, and Nathan S. Lewis* \\ Beckman Institute and Kavli Nanoscience Institute, Division of Chemistry and Chemical Engineering, 210 Noyes Laboratory, 127-72, \\ California Institute of Technology, Pasadena, California 91125, United States
}

\section{Supporting Information}

ABSTRACT: The photoelectrochemical behavior of n-type $\mathrm{ZnO}$ nanowire arrays was compared to the behavior of single crystalline $\mathrm{n}-\mathrm{ZnO}$ photoelectrodes in contact with either $0.50 \mathrm{M} \mathrm{K}_{2} \mathrm{SO}_{4}(\mathrm{aq})$ at $\mathrm{pH} 6.0$ or $\mathrm{Fe}(\mathrm{CN})_{4}{ }^{3-/ 4-}(\mathrm{aq})$. The use of a thin film of $\mathrm{ZnO}$ as a seed layer produced dense nanowire arrays in which the $\mathrm{ZnO}$ nanowires were preferentially oriented perpendicular to the substrate. The average diameter of the $\mathrm{ZnO}$ nanowires that were produced by two different growth conditions was $\sim 125$ and $\sim 175 \mathrm{~nm}$, respectively, with a nanowire length of $\sim 2-4 \mu \mathrm{m}$. Under simulated 1 Sun Air Mass 1.5 illumination conditions, the $\mathrm{ZnO}$ nanowire arrays exhibited open-circuit potentials, $E_{\text {oc }}$ and short-circuit photocurrent densities, $J_{s c}$ that were very close to the values observed from single crystal ntype $\mathrm{ZnO}$ photoanodes in contact with these same electrolytes. Device physics simulations were in accord with the experimentally observed behavior, indicating that, under certain combinations of materials properties and interface recombination velocities, the use of nanostructured light absorbers can provide an approach to efficient photoelectrochemical solar energy-conversion systems.

\section{INTRODUCTION}

Nanowire and microwire arrays allow the orthogonalization of light absorption and charge-carrier collection, thereby, in principle, enabling high solar energy-conversion efficiencies to be obtained from material that has a short minority-carrier collection length. Under Air Mass (AM) 1.5 conditions, in structures that only absorbed $\sim 50 \%$ of the incident photons above the band gap of the absorber, Si microwire arrays have yielded $7.9 \%^{1}$ energy-conversion efficiencies for solar electricity production, as well as thermodynamically based efficiencies of $>5 \%{ }^{2}$ as photocathodes for the evolution of $\mathrm{H}_{2}$ from $\mathrm{H}_{2} \mathrm{O}$.

In contrast to the high energy-conversion efficiencies reported for microwire-based solar devices, despite extensive investigation, including preparation by chemical vapor deposition, templated electrodeposition, wet chemical techniques, and other methods, ${ }^{3-28}$ relatively few efficient solar energyconversion systems have been reported using nanowire-based light absorbers. For photoanodes, nanoparticulate metal oxides and metal oxide thin films have been widely explored. ${ }^{29-31}$ Specifically, when used as a photoanode for water oxidation, $\mathrm{TiO}_{2}$ nanorods formed by the anodization of titanium ${ }^{32}$ have exhibited internal quantum yields of 0.9 at incident photon wavelengths of $337 \mathrm{~nm},{ }^{33}$ and photoanodes made from arrays of $\mathrm{ZnO}$ nanorods grown by sputter deposition have exhibited photocurrent densities under white light illumination of $\sim 20$ $\mathrm{uA} \mathrm{cm}{ }^{-2}$ at $1 \mathrm{~V}$ vs $\mathrm{Ag} / \mathrm{AgCl}^{34}$ Nanorod arrays of metal oxides such as $\mathrm{Fe}_{2} \mathrm{O}_{3}$ or $\mathrm{ZnO}$ have been grown using a lowtemperature solution-based approach. ${ }^{23,24,35,36} \mathrm{Fe}_{2} \mathrm{O}_{3}$ nanorod photoanodes have not exhibited significant efficiency improve-

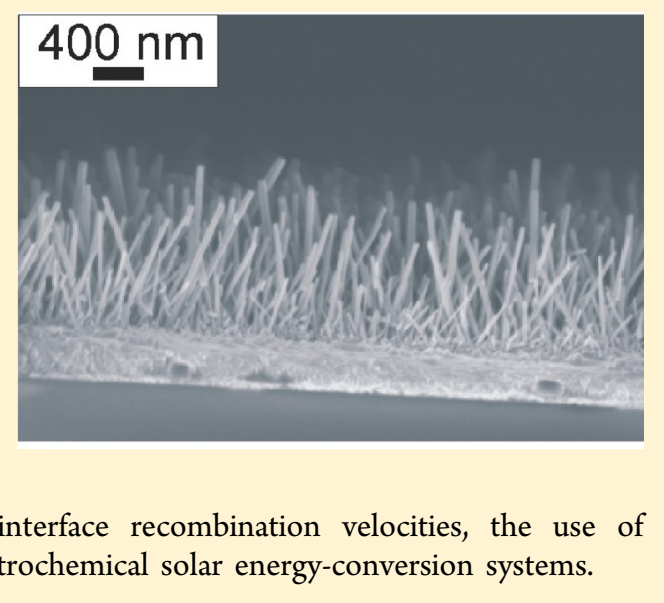

ments relative to $\mathrm{Fe}_{2} \mathrm{O}_{3}$ thin films. $\mathrm{ZnO}$ nanorod arrays that were grown by a solution-based method ${ }^{22,37-39}$ have been used in dye-sensitized solar cells and in photovoltaics. ${ }^{40-42}$

A recent analysis based on a device physics model has concluded that, under many circumstances of dopant density and radius, nanowires will exhibit poor energy-conversion efficiencies relative to bulk absorbers. ${ }^{43}$ A question of interest is thus whether, in general, strategies to produce efficient solar energy-conversion systems should preferentially focus on microwires relative to nanowires or other nanostructured morphologies of the light absorber. Notably, good performance with nanostructures has been reported in some instances, including the specific examples of $\mathrm{p}$-i-n core/shell $\mathrm{Si}$ single nanowire photovoltaics ${ }^{44}$ and $\mathrm{CdSeTe}$ nanowire arrays used as photoanodes in a regenerative photoelectrochemical cell configuration. ${ }^{45}$

In this work, we have directly compared the photoanodic performance of $\mathrm{ZnO}$ nanowires to the photoanodic performance of $\mathrm{ZnO}$ single crystals. $\mathrm{ZnO}$ is a well-established photoanode for water oxidation; ${ }^{34}$ furthermore, the aqueous electrolyte provides a conformal contact that conveniently facilitates a comparison between the charge separation and charge-collection properties of bulk samples and nanostructured array-type photoelectrodes. Arrays of $\mathrm{ZnO}$ nanowires that are oriented preferentially in a vertical direction can be

Received: October 4, 2012

Revised: December 10, 2012

Published: December 14, 2012 
obtained using low-temperature solution growth techniques. ${ }^{23}$ In this work, the photoelectrochemical behavior of such $\mathrm{ZnO}$ nanowire arrays has been investigated in contact with aqueous electrolytes, as a photoanode for the oxidation of water as well as for the oxidation of $\mathrm{Fe}(\mathrm{CN})_{6}^{4-}$, to understand whether fundamental differences in behavior are present between kinetically slow multielectron interfacial charge-transfer processes relative to rapid, one-electron, interfacial charge-transfer processes that would allow for suppression of recombination and enable efficient charge-carrier collection at nanowire array photoelectrodes. We also have compared the experimental data to the predictions of a device physics model that incorporates the geometric and electrical properties of the $\mathrm{ZnO}$ structures under investigation, to facilitate a comparison between theory and experiment for the photoelectrochemical behavior of vertically oriented arrays of semiconducting nanowires.

\section{EXPERIMENTAL SECTION}

A. Chemicals. All chemicals, including zinc nitrate hexahydrate 98\% (Aldrich) and hexamethylenetetramine 98\% (Aldrich), were used as received. Water was $18 \mathrm{M} \Omega \mathrm{cm}$ in resistivity, as obtained from a Barnsted Nanopure system.

B. Electrode Materials. The $\mathrm{ZnO}$ single crystals were oriented to expose the (0001) surface plane (MTI Corp) and were polished on one side. Ohmic contact to the back side of the crystal was made using In/Ga eutectic. ${ }^{46} \mathrm{Ag}$ print was then used to attach tinned $\mathrm{Cu}$ wire to the back of the sample, and the fully assembled electrodes were sealed by the use of white epoxy (Hysol 1C).

$\mathrm{ZnO}$ nanowire arrays were grown by a slight modification of the method of Vayssieres. ${ }^{23}$ The process provided control over the diameter of the nanowires, through variation of the concentration of reagents in the solution, as well as over the length of the wires, through variation of the growth time. A thin film of $\mathrm{ZnO}$, prepared by sputtering $\sim 20 \mathrm{~nm}$ of $\mathrm{Zn}$ (RF magnetron sputterer, $\mathrm{Zn}$ target of $99.99 \%$ purity from Kurt J. Lesker Company) onto a glass slide that had been coated with fluorine-doped tin oxide (FTO), seeded the nanowire growth and increased the density of the wires in the array. Prior to wire growth, a portion of the FTO was masked, to allow for subsequent formation of an electrical contact. The $\mathrm{Zn}$ was thermally oxidized at $400{ }^{\circ} \mathrm{C}$ for $2 \mathrm{~h}$ under a continuous flow of air. The bare FTO was coated with a layer of nail polish, and the slides were then placed diagonally in the aqueous growth solution, with the face of the $\mathrm{ZnO}$ seed layer pointing downward. $\mathrm{ZnO}$ wires that were $2 \mu \mathrm{m}$ in length were produced from either a 5 or $50 \mathrm{mM}$ solution of $\mathrm{Zn}\left(\mathrm{NO}_{3}\right)_{2}$ and hexamethylenetetramine, at $95{ }^{\circ} \mathrm{C}$. To grow longer wires, the slide was placed in a fresh solution every $4 \mathrm{~h}$. The slides were then cooled and rinsed with water, and the nail polish mask was removed with acetone. Before use, the wire arrays were annealed at $450{ }^{\circ} \mathrm{C}$ for $1 \mathrm{~h}$ in air.

Electrodes were formed from the nanowire arrays by attaching a $\mathrm{Cu}$ wire to the back of the FTO-coated glass slide, and using Ag print to contact the bare FTO on the front side of the electrode. The electrode was then sealed in white epoxy. Electrode areas were measured by digitizing photographs of a ruler and of the exposed electrode area. Electrodes were etched in $1 \mathrm{M} \mathrm{H}_{2} \mathrm{SO}_{4}$ prior to electrochemical measurements.

C. Single-Wire Resistance Measurements. The $\mathrm{ZnO}$ nanowires were removed from the substrate by sonicating the wires in ethanol. The wires were then spin-cast onto a degenerately doped n-type Si wafer that had been coated with $300 \mu \mathrm{m}$ of thermally grown $\mathrm{Si}$ oxide. Contacts were patterned onto individual wires by use of electron-beam lithography. The location, and alignment, of the $\mathrm{ZnO}$ wires was performed by use of probe tips in a scanning-electron microscope (SEM). Low accelerating voltages and beam currents were used to prevent complete exposure of the polymethylmethylacrylate (PMMA). After development of the PMMA, $250 \mathrm{~nm}$ of Ti and $50 \mathrm{~nm}$ of Au was deposited by electron-beam evaporation. The conductivity was measured using the evaporated metal probes and converted to a carrier concentration assuming an electron mobility of $44 \mathrm{~cm}^{2} \mathrm{~V}^{-1} \mathrm{~s}^{-1}$ using standard relationships between carrier concentration, mobility, and resistivity.

D. Characterization. X-ray photoelectron spectroscopy (XPS) was performed with an M-Probe XPS system. ${ }^{4,48}$ The instrument provided $1486.6 \mathrm{eV}$ X-rays from an $\mathrm{Al} \mathrm{K} \alpha$ source. The sample was illuminated at an incident angle of $35^{\circ}$ off of the surface. The photoelectrons that were emitted along a trajectory of $35^{\circ}$ off of the surface plane were collected by a hemispherical analyzer. All of the samples were sufficiently conductive that no compensation for charging effects was required.

X-ray diffraction spectra were obtained on a PANanlytical X'pert pro diffractometer. Electronic absorption spectra were obtained using an Agilent $8453 \mathrm{UV}-$ vis diode array spectrometer.

E. Electrochemistry and Photoelectrochemistry. Electrochemical measurements were performed at a scan rate of 50 $\mathrm{mV} \mathrm{s}^{-1}$, using a Bioanalytical Systems Model 100B potentiostat, with a $\mathrm{ZnO}$ working electrode, a platinum mesh counter electrode, and a standard calomel electrode (SCE) as the reference electrode. The $\mathrm{pH}$ of the as-produced 0.50 $\mathrm{K}_{2} \mathrm{SO}_{4}(\mathrm{aq})$ electrolyte was measured to be 6.0. The formal potential for the $\mathrm{O}_{2} / \mathrm{H}_{2} \mathrm{O}$ redox system in this electrolyte was $+0.635 \mathrm{~V}$ vs SCE, as calculated by the Nernst equation. For measurements at $\mathrm{pH} 11.0$, the $\mathrm{pH}$ was adjusted to the desired value by addition of $0.10 \mathrm{M} \mathrm{NaOH}(\mathrm{aq})$.

The aqueous $\mathrm{Fe}(\mathrm{CN})_{6}^{3-/ 4-}$ cell was prepared from a solution of $10 \mathrm{mM} \mathrm{K}_{4} \mathrm{Fe}(\mathrm{CN})_{6}$ in $0.5 \mathrm{M} \mathrm{K}_{2} \mathrm{SO}_{4}$. Approximately $1 \mathrm{mM}$ of $\mathrm{Fe}(\mathrm{CN})_{6}{ }^{3-}$ was synthesized by bulk electrolysis at $0 \mathrm{~V}$ vs SCE, producing a solution that had a Nernstian potential of $+0.225 \mathrm{~V}$ vs SCE.

The light source was either an Oriel Inc. solar simulator, with AM 1.5 filters, adjusted to produce an intensity equivalent to $100 \mathrm{~mW} \mathrm{~cm} \mathrm{c}^{-2}$ of solar illumination on a calibrated, secondary standard, Si photodiode (Solarex), or was a $200 \mathrm{~W}$ mercury lamp with a $365 \mathrm{~nm} \mathrm{Hg}$ line filter that had a $5 \mathrm{~nm}$ full width at half-maximum spectral window. The light entered the electrochemical cell through a Pyrex window.

F. Spectral Response. Spectral response data were obtained using a $75 \mathrm{~W}$ Xe lamp with a Cornerstone 2601 1/ $4 \mathrm{~m}$ dual grating monochromator. The electrode was maintained potentiostatically at $+0.350 \mathrm{~V}$ vs SCE in a $\mathrm{pH} 11$ solution of $0.5 \mathrm{M} \mathrm{K}_{2} \mathrm{SO}_{4}$. The photocurrent was measured every $5 \mathrm{~nm}$. The quantum yield was determined by comparing the response of the photoelectrode to the response of a photodiode (UDT Sensors Inc.) that had been calibrated every $10 \mathrm{~nm}$ from 200 to $1100 \mathrm{~nm}$, with the response data interpolated to produce quantum yields every $5 \mathrm{~nm}$.

G. Device Physics Simulations. The photoelectrochemical properties of planar and nanowire $\mathrm{ZnO}$ electrodes were simulated using Sentaurus Device software (Synopsys, Inc.). The simulations were performed in two dimensions, and the 
optical excitation source was assumed to be $100 \mathrm{~mW} \mathrm{~cm}^{-2}$ of AM 1.5 illumination. Wires that had a radial solution contact were simulated in cylindrical coordinates. The solution contact was modeled as a Schottky contact with a work function of 5.5 $\mathrm{eV}$. Unless otherwise stated, the parameters used for $\mathrm{ZnO}$ were as follows: electron affinity $=3.7 \mathrm{eV}$; band gap $=3.3 \mathrm{eV}$; electron mobility $=50 \mathrm{~cm}^{2} \mathrm{~V}^{-1} \mathrm{~s}^{-1}$; hole mobility $=10 \mathrm{~cm}^{2} \mathrm{~V}^{-1}$ $\mathrm{s}^{-1}$; electron lifetime $=$ hole lifetime $=1 \mathrm{~ns}$; doping density $\left(N_{\mathrm{D}}\right)=5 \times 10^{17} \mathrm{~cm}^{-3}$. The simulation mesh had a minimum dimension of $8 \mathrm{~nm}$ but a tighter mesh was used near the electrode interfaces (Supporting Information). The simulations assumed a diameter of $125 \mathrm{~nm}$ and length of $4 \mu \mathrm{m}$ for the $\mathrm{ZnO}$ nanowires. The planar simulations assumed a $\mathrm{ZnO}$ film thickness of $4 \mu \mathrm{m}$. The electron and hole recombination velocities, respectively, at the surface were each set at $1 \times 10^{7}$ $\mathrm{cm} \mathrm{s}^{-1}$. Surface recombination was modeled by specifying the electron and hole recombination velocities at the contacts.

\section{RESULTS}

A. Composition, Morphology, Optical, and Electrical Properties of ZnO Nanowire Arrays. The use of a thin film of $\mathrm{ZnO}$ as a seed layer for rod growth produced dense nanowire arrays, preferentially oriented perpendicular to the substrate. Decreases in the concentration of the $1: 1$ zinc nitrate:hexamethylenetetramine solution produced a decrease in the average wire diameter. The average diameter of $\mathrm{ZnO}$ nanowires for a $4 \mathrm{~h}$ growth time at $95{ }^{\circ} \mathrm{C}$ in the 5 and $50 \mathrm{mM}$ growth solutions was $\sim 40$ and $\sim 125 \mathrm{~nm}$, respectively (Figure 1). After $4 \mathrm{~h}$, the wire lengths were $1.4 \mu \mathrm{m}$ for the $5 \mathrm{mM}$ solution and $2.1 \mu \mathrm{m}$ for the $50 \mathrm{mM}$ solution. Although growth stopped after $4 \mathrm{~h}$, exposure of the nanowires to a fresh solution reinitiated the growth of the wires. Thus, heating a new $50 \mathrm{mM}$ growth solution for an additional $4 \mathrm{~h}$ increased the wire length to $4 \mu \mathrm{m}$. The second growth resulted in the wires doubling in
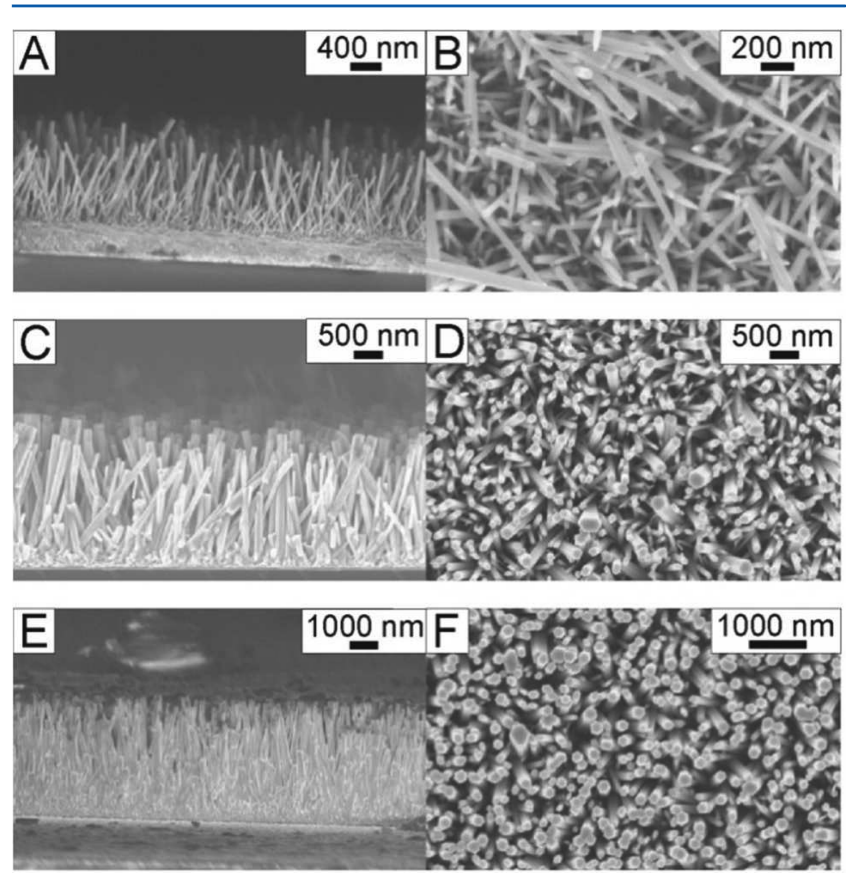

Figure 1. SEM images of the side and top view of $\mathrm{ZnO}$ nanorods grown from a $5 \mathrm{mM}$ solution for $4 \mathrm{~h}(\mathrm{~A}, \mathrm{~B})$, from a $50 \mathrm{mM}$ solution for $4 \mathrm{~h}(\mathrm{C}, \mathrm{D})$, and from a $50 \mathrm{mM}$ solution for $4 \mathrm{~h}$ followed by $4 \mathrm{~h}$ in a fresh $50 \mathrm{mM}$ growth solution (E, F). length but only produced a slight increase in the diameter, to $\sim 175 \mathrm{~nm}$.

$\mathrm{X}$-ray diffraction (XRD) measurements indicated that the nanowire arrays were composed of crystalline $\mathrm{ZnO}$ (Figure 2).

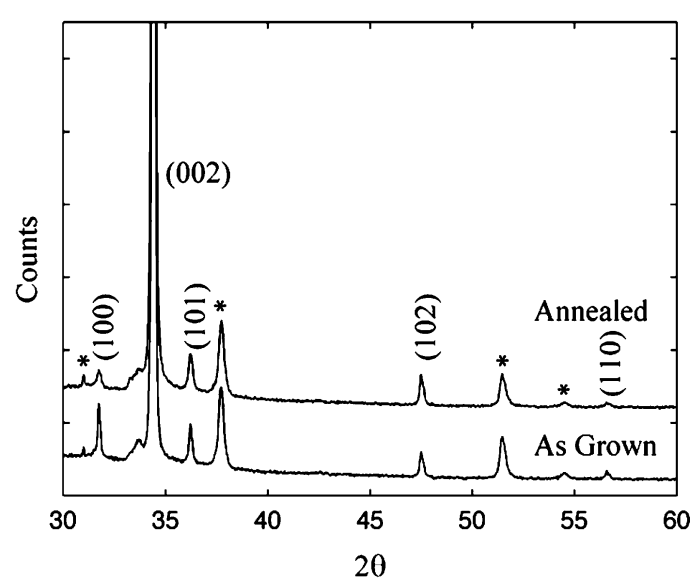

Figure 2. $\mathrm{XRD}$ patterns of as-grown and annealed $\mathrm{ZnO}$ nanorods on a FTO substrate (FTO peaks denoted with an asterisk).

The rods grew along the (0001) axis, with this growth axis vector oriented preferentially perpendicular to the substrate. The (002) peak was more pronounced than other $\mathrm{ZnO}$ peaks, as expected due to the orientation of the nanowires. Annealing of the arrays at $450{ }^{\circ} \mathrm{C}$ for $1 \mathrm{~h}$ had a negligible effect on the crystalline quality of the films, as probed by XRD.

Figure 3 depicts the XPS data of $\mathrm{ZnO}$ nanowires before and after annealing at $450{ }^{\circ} \mathrm{C}$ for $1 \mathrm{~h}$ in air. Prior to the anneal, $\mathrm{N} 1 \mathrm{~s}$ and $\mathrm{C} 1 \mathrm{~s}$ signals, indicative of surface contamination by the organic compounds in the growth solution, were detected in the XPS scans. The high binding energy of the $\mathrm{N}$ signal indicated that the $\mathrm{N}$ species was in a highly oxidized state and was bonded to a number of oxygen atoms. After annealing, no $\mathrm{N}$ peak was observed. In the $\mathrm{C} 1 \mathrm{~s}$ region, the main peak, observed at $286 \mathrm{eV}$, can be assigned to adventitious carbon, while the shoulder at higher binding energy can be associated with the organic contaminant. After annealing, the $\mathrm{C}$ peak was reduced in intensity and shifted to higher binding energy, suggesting that some of the $\mathrm{C}$ contamination had been oxidized and then removed from the sample.

Figure 4 displays the UV-visible absorbance spectra of $2 \mu \mathrm{m}$ long $\mathrm{ZnO}$ rods that were obtained from the $5 \mathrm{mM}$ growth solution. The absorption onset of the $\mathrm{ZnO}$ nanowires occurred near $3.2 \mathrm{eV}$, which corresponds well with the literature values for the $\mathrm{ZnO}$ band gap of 3.2-3.3 eV. The absorbance exceeded 1.0 at energies slightly above the band gap, indicating that the wire array was sufficiently long and dense to absorb most of the incident UV light. Nanowire arrays produced by the $50 \mathrm{mM}$ growth solution scattered too much light to allow for reliable transmission measurements, but presumably the absorbance spectrum of these films was similar to, if not higher than, that of the arrays obtained from the $5 \mathrm{mM}$ growth solution, due to the denser nanowire structure produced by the $50 \mathrm{mM}$ growth solution.

Four-point resistivity measurements (between $\mathrm{Ti} / \mathrm{Au}$ contacts that were patterned on single $\mathrm{ZnO}$ nanowires by electronbeam lithography) showed that the $\mathrm{ZnO}$ nanowires were highly conductive, with resistivities of $0.2 \Omega-\mathrm{cm}$. The measured resistivity is in agreement with previously reported values for 

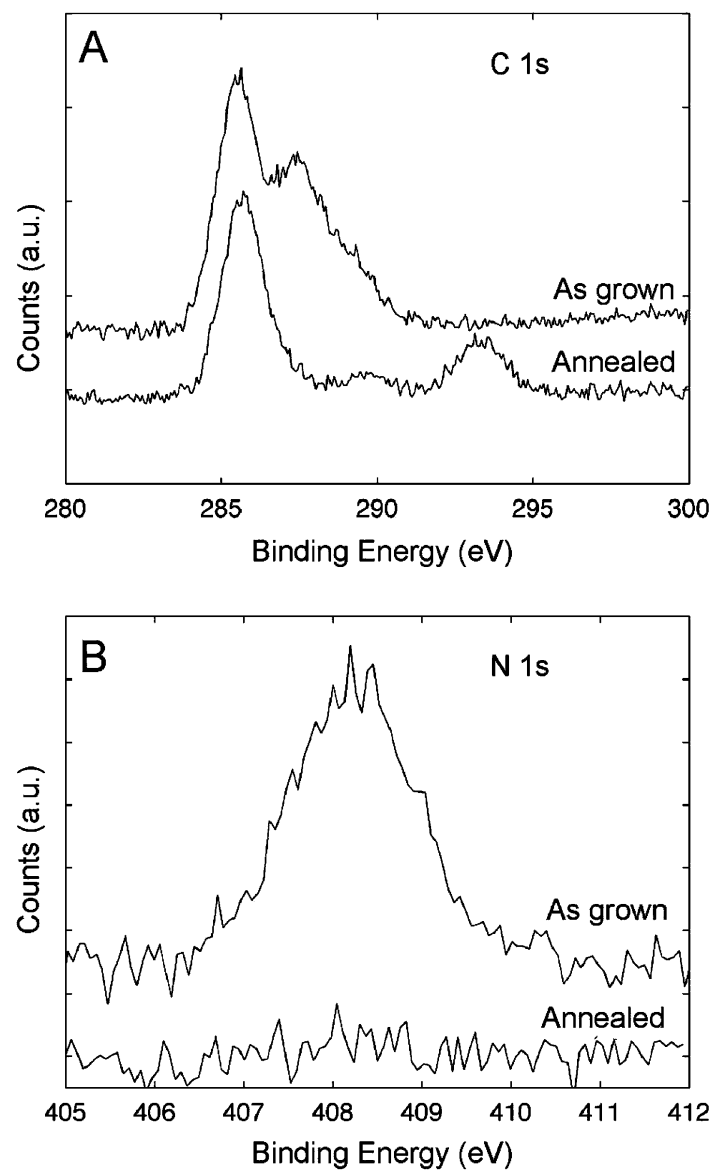

Figure 3. X-ray photoelectron spectra of the $\mathrm{C} 1 \mathrm{~s}$ (A) and $\mathrm{N}$ 1s (B) regions of $\mathrm{ZnO}$ nanorods before and after annealing.

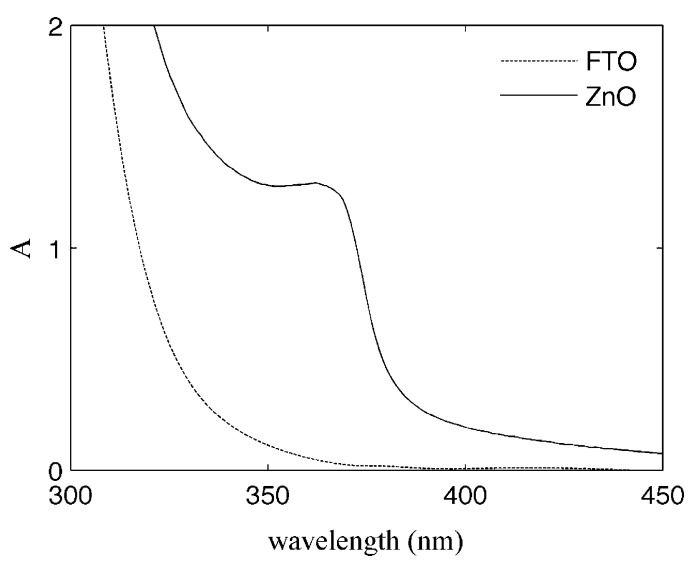

Figure 4. UV-visible absorbance spectra of $\mathrm{ZnO}$ nanorods and of the FTO substrate.

$\mathrm{ZnO}$ nanowires that were grown by chemical vapor deposition methods. ${ }^{9}$ For a built-in voltage, $V_{\mathrm{bi}}$ of $1.8 \mathrm{~V}$, the reported electron mobilities for $\mathrm{ZnO}$ nanowires (ranging from 13 to 75 $\mathrm{cm}^{2} \mathrm{~V}^{-1} \mathrm{~s}^{-19,25}$ ) yielded a calculated depletion width of $\sim 60$ $\mathrm{nm}$. The assumed mobility for electrons was $44 \mathrm{~cm}^{2} \mathrm{~V}^{-1} \mathrm{~s}^{-1}$, which is the average of the reported values. The $125 \mathrm{~nm}$ and $175 \mathrm{~nm}$ diameter $\mathrm{ZnO}$ nanowires therefore had radii that were slightly larger than their calculated depletion width.

B. Current Density vs Potential Behavior of Single Crystal ZnO vs Nanowire ZnO Photoanodes. Figure 5 shows the current density vs potential $(J-E)$ behavior, in the

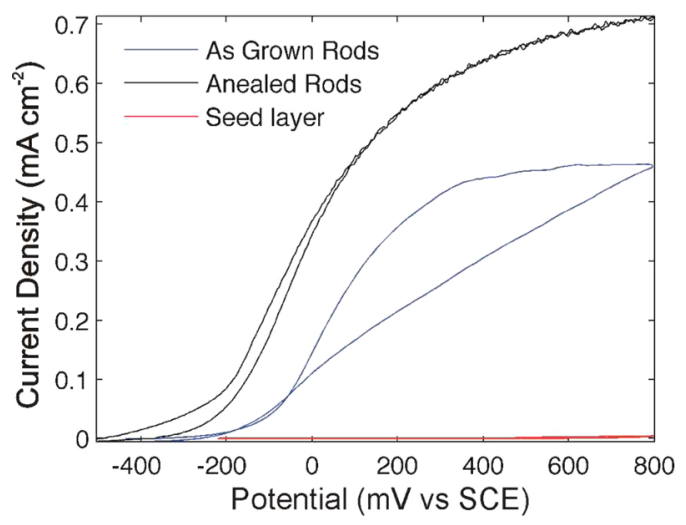

Figure 5. $J-E$ behavior under $365 \mathrm{~nm}$ illumination in $0.5 \mathrm{M} \mathrm{K}_{2} \mathrm{SO}_{4}$ of a $\mathrm{ZnO}$ seed layer (red), a $\mathrm{ZnO}$ nanorod array prior to annealing (blue), and a $\mathrm{ZnO}$ nanorod array after annealing (black).

presence of $365 \mathrm{~nm}$ illumination, of the $\mathrm{ZnO}$ seed layer, of asgrown $\mathrm{ZnO}$ nanorod arrays (diameter $=125 \mathrm{~nm}$ ), and of annealed $\mathrm{ZnO}$ nanorods, respectively, in contact with $0.5 \mathrm{M}$ $\mathrm{K}_{2} \mathrm{SO}_{4}(\mathrm{aq})$. The annealed wire arrays yielded larger current densities and photovoltages than unannealed wire arrays. Wires that were grown for $4 \mathrm{~h}$ from the $5 \mathrm{mM}$ growth solution yielded photocurrents that quickly degraded, whereas wires grown for 4 $\mathrm{h}$ from the $50 \mathrm{mM}$ growth solution produced stable photocurrents for $>3 \mathrm{~h}$ of continuous illumination at an electrode potential, $E$, of $+0.35 \mathrm{~V}$ vs SCE. Negligible photocurrent was produced by the $\mathrm{ZnO}$ thin film seed layer.

Figure 6 compares the $J-E$ responses, under $100 \mathrm{~mW} \mathrm{~cm}^{-2}$ of simulated AM 1.5 illumination, as well as in the absence of

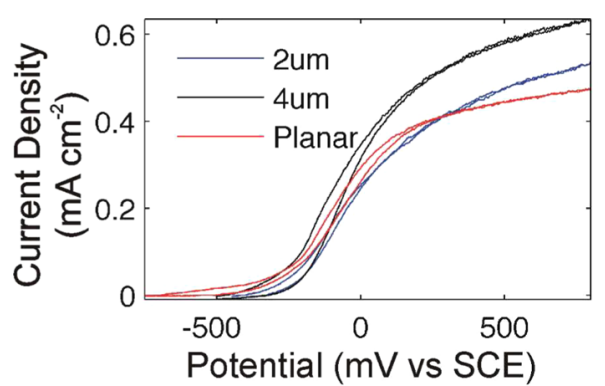

Figure 6. AM 1.5 response for $\mathrm{ZnO}$ single crystal (red) and optimized $4 \mu \mathrm{m}$ wire arrays (black) and $2 \mu \mathrm{m}$ wire arrays (blue) measured in 0.5 $\mathrm{M} \mathrm{K}_{2} \mathrm{SO}_{4}$ at $\mathrm{pH}$ 6.4.

illumination, of the $\mathrm{ZnO}$ single crystals to that of the optimized $\mathrm{ZnO}$ nanowire arrays. The photoelectrodes exhibited opencircuit potentials, $E_{\mathrm{oc}}$ of $-605 \mathrm{mV}$ vs SCE for the single crystal and $E_{\mathrm{oc}}=-390 \mathrm{mV}$ vs SCE for the $4 \mu \mathrm{m}$ wire array samples, respectively. The current density at $E=+400 \mathrm{mV}$ vs SCE was largest for the $4 \mu \mathrm{m}$ wire arrays, having a value of $J=0.55 \mathrm{~mA}$ $\mathrm{cm}^{-2}$.

Table 1 presents a comparison of the energy-conversion efficiencies of $\mathrm{ZnO}$ nanowire arrays and single crystals of $\mathrm{ZnO}$. The potential of the SCE was used as the reference potential to determine the photovoltage produced by the $\mathrm{ZnO}$ electrode under AM 1.5 illumination. The photovoltage of the single crystalline $\mathrm{ZnO}$ exceeded the photovoltages exhibited by the $\mathrm{ZnO}$ nanowire arrays.

Figure 7 and Table 2 present the $J-E$ behavior under the same conditions but with the illumination passed through a 385 $\mathrm{nm}$ long pass filter. Under such conditions, the wire arrays 
Table 1. AM 1.5 Response for a ZnO Single Crystal, 2 and 4 $\mu \mathrm{m}$ in Length $\mathrm{ZnO}$ Nanowire Arrays in $0.5 \mathrm{M} \mathrm{K}_{2} \mathrm{SO}_{4}$ at $\mathrm{pH}$ 6.4 with $\mathrm{O}_{2}$ Bubbling

\begin{tabular}{llll} 
& \multicolumn{1}{c}{$2 \mu \mathrm{m}$} & \multicolumn{1}{c}{$4 \mu \mathrm{m}$} & single crystal \\
$J_{\mathrm{sc}}\left(\mathrm{mA} / \mathrm{cm}^{2}\right)$ & $0.510 \pm 0.01$ & $0.600 \pm 0.03$ & 0.458 \\
$E_{\mathrm{oc}}(\mathrm{mV}$ vs SCE $)$ & $-365 \pm 10$ & $-390 \pm 15$ & -605 \\
$\mathrm{ff}$ & $0.34 \pm 0.01$ & $0.36 \pm 0.01$ & 0.34 \\
\hline
\end{tabular}

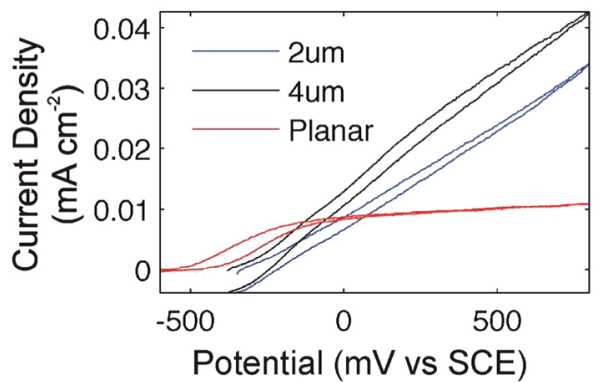

Figure 7. $J-E$ behavior in $0.5 \mathrm{M} \mathrm{K}_{2} \mathrm{SO}_{4}$ with $\mathrm{O}_{2}$ bubbling under $\mathrm{AM}$ 1.5 illumination with a $385 \mathrm{~nm}$ long pass filter: single crystal (red) $\mathrm{ZnO}, 4 \mu \mathrm{m}$ length $\mathrm{ZnO}$ wires (black), and $2 \mu \mathrm{m}$ length $\mathrm{ZnO}$ wires (blue).

Table 2. AM 1.5 with 385 nm Long Pass Filter Response for $\mathrm{ZnO}$ Single Crystal, 2 and $4 \mu \mathrm{m}$ in Length $\mathrm{ZnO}$ Nanowire Arrays in $0.5 \mathrm{M} \mathrm{K}_{2} \mathrm{SO}_{4}$ with $\mathrm{O}_{2}$ Bubbling

\begin{tabular}{llll} 
& \multicolumn{1}{c}{$2 \mu \mathrm{m}$} & \multicolumn{1}{c}{$4 \mu \mathrm{m}$} & single crystal \\
$J_{\mathrm{sc}}\left(\mathrm{mA} / \mathrm{cm}^{2}\right)$ & $0.027 \pm 0.002$ & $0.039 \pm 0.004$ & 0.01 \\
$E_{\mathrm{oc}}(\mathrm{mV}$ vs SCE $)$ & $-265 \pm 7$ & $-309 \pm 6$ & -522 \\
$\mathrm{ff}$ & $0.26 \pm 0.01$ & $0.27 \pm 0.01$ & 0.5 \\
\hline
\end{tabular}

produced $J=39 \mu \mathrm{A} \mathrm{cm}^{-2}$ at $E=+0.400 \mathrm{~V}$ vs SCE, whereas single crystals of $\mathrm{ZnO}$ produced $J=10 \mu \mathrm{A} \mathrm{cm}^{-2}$ at $E=+0.400$ $\mathrm{V}$ vs SCE. Thus, under AM 1.5 illumination, the $\mathrm{ZnO}$ single crystals generated a larger photovoltage than the $\mathrm{ZnO}$ nanowire arrays, while the wires produced slightly more current with the $385 \mathrm{~nm}$ long pass filter (Table 2).

Figure 8 shows the $J-E$ behavior of $175 \mathrm{~nm}$ diameter nanowires in contact with $\mathrm{Fe}(\mathrm{CN})_{6}^{3-/ 4-}(\mathrm{aq})$. The wire arrays produced photovoltages of $510 \mathrm{mV}$ vs the Nernstian potential of the solution, and produced $J_{\mathrm{sc}}$ values of $0.35 \mathrm{~mA} \mathrm{~cm}^{-2}$. The $J_{\text {sc }}$ values measured in contact with $\mathrm{Fe}(\mathrm{CN})_{6}^{3-/ 4-}$ aqueous

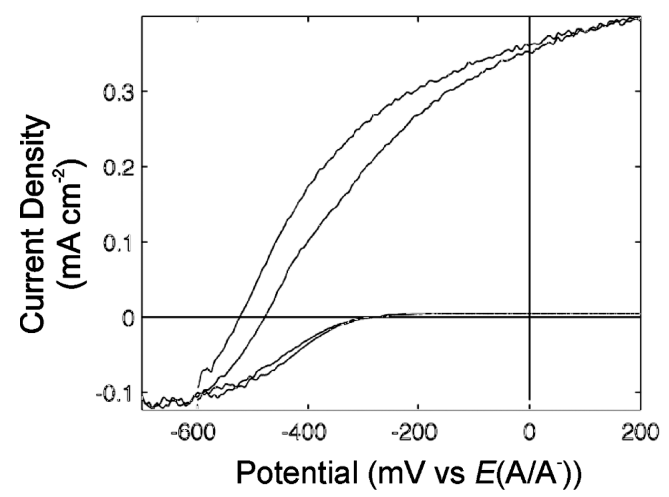

Figure 8. Response in the presence and absence of $100 \mathrm{~mW} \mathrm{~cm}^{-2}$ of simulated AM 1.5 illumination for $4 \mu \mathrm{m}$ long, $175 \mathrm{~nm}$ diameter, $\mathrm{ZnO}$ nanowire arrays in contact with $10 \mathrm{mM} \mathrm{Fe}(\mathrm{CN})_{6}^{4-}-1 \mathrm{mM}$ $\mathrm{Fe}(\mathrm{CN})_{6}{ }^{3-}-0.5 \mathrm{M} \mathrm{K}_{2} \mathrm{SO}_{4}(\mathrm{aq})$. solutions were less than those measured in contact with $\mathrm{K}_{2} \mathrm{SO}_{4}(\mathrm{aq})$ solutions, as expected due to optical absorption by the $\mathrm{Fe}(\mathrm{CN})_{6}^{3-/ 4-}$ redox species.

C. Spectral Response of ZnO Nanowire Array Photoanodes. Figure 9 displays the spectral response behavior of

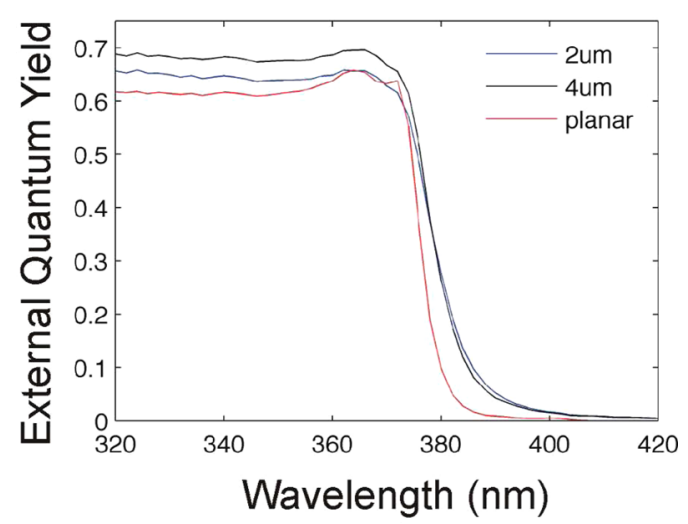

Figure 9. Spectral response in $0.5 \mathrm{M} \mathrm{K}_{2} \mathrm{SO}_{4}$ at $\mathrm{pH} 11$ and at $E=+0.35$ $\mathrm{V}$ vs SCE of $4 \mu \mathrm{m}$ diameter $\mathrm{ZnO}$ wires (black), $2 \mu \mathrm{m}$ diameter $\mathrm{ZnO}$ wires (blue), and a single crystal $\mathrm{ZnO}$ photoelectrode (red).

$\mathrm{ZnO}$ single crystals and $\mathrm{ZnO}$ nanowire array photoanodes in contact with $0.5 \mathrm{M} \mathrm{K}_{2} \mathrm{SO}_{4}$ at $\mathrm{pH} 6.5$ and at $E=+0.35 \mathrm{~V}$ vs SCE. Both electrodes showed maximum external quantum yields in excess of 0.7. The single crystal exhibited a slightly lower external quantum yield at energies just slightly above the band gap.

D. Device Physics Simulations. A finite-element device physics model was used to simulate the photoelectrochemical properties of planar and nanowire-array $\mathrm{ZnO}$ electrodes (Figure 10). The solution contact was modeled as a Schottky-type

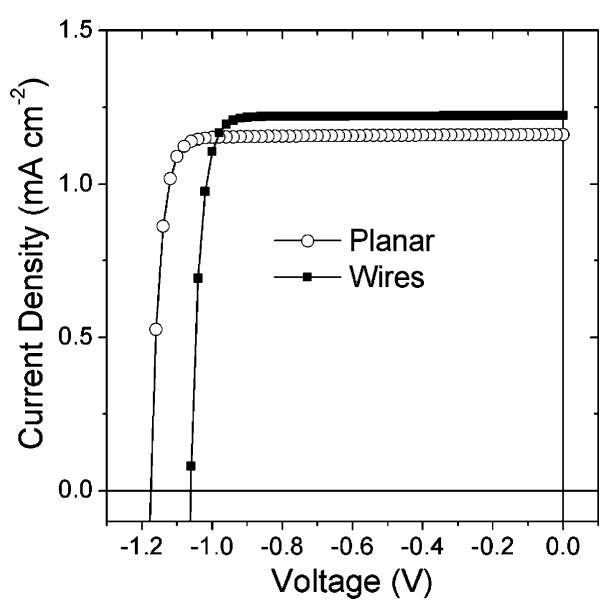

Figure 10. Simulated $J-V$ responses of a planar and wire array $\mathrm{ZnO}$ photoelectrode in contact with a high barrier height Schottky-type contact.

contact that had a contact potential difference of $1.8 \mathrm{~V}$. The geometries, and the electrical properties, of the $\mathrm{ZnO}$ nanowires in the array were modeled to be in accord with the values appropriate for the $\mathrm{ZnO}$ wires as well as for the $\mathrm{ZnO}$ planar samples that were used in the experiments reported herein.

The integrated total absorption, the spatial absorption profile, and material electronic properties were identical for the $\mathrm{ZnO}$ planar and $\mathrm{ZnO}$ nanowire geometries. The simulation 
yielded slightly larger $V_{\text {oc }}$ values for the planar devices $V=1.17$ $\mathrm{V}$ than for the nanowire devices $V=1.06 \mathrm{~V}$. $J_{\mathrm{sc}}$ values were slightly smaller for planar devices $J_{\mathrm{sc}}=1.16 \mathrm{~mA} \mathrm{~cm}{ }^{-2}$ than for nanowire analogues $J_{\mathrm{sc}}=1.22 \mathrm{~mA} \mathrm{~cm}{ }^{-2}$. The short-circuit current densities were also simulated for wires that had a variety of diameters and lifetimes (Figure S1, Supporting Information). The simulations predicted a steep decline in the $J_{\mathrm{sc}}$ values near $\mathrm{ZnO}$ nanowire diameters of $75 \mathrm{~nm}$. For the doping density observed experimentally, the value of the depletion width

$$
W=\left(\frac{2 \epsilon_{\mathrm{s}} V_{\mathrm{BI}}}{q N_{\mathrm{D}}}\right)^{1 / 2}
$$

is $\sim 60 \mathrm{~nm}$, where $V_{\mathrm{BI}}$ is the built-in voltage, $N_{\mathrm{D}}$ is the dopant density, $q$ is the unsigned charge of an electron, and $\varepsilon_{\mathrm{s}}$ is the dielectric constant of the $\mathrm{ZnO}$. Thus, the $J_{\mathrm{sc}}$ values declined rapidly at wire diameters, $d$, for which $d<2 W$.

\section{DISCUSSION}

A. Spectral Response. The combination of high absorption (Figure 4) and nearly unity external quantum yields (Figure 9) indicates that, other than a relatively small amount of reflection, nearly all incident light above the band gap energy was absorbed by the $\mathrm{ZnO}$ single crystals and nanowires, respectively. The higher external quantum yields near the absorption edge that were observed for the $\mathrm{ZnO}$ wires relative to $\mathrm{ZnO}$ planar samples (Figure 9) are consistent with the higher current densities that were observed for the wire array electrodes under illumination with the $385 \mathrm{~nm}$ long pass filter (Figure 7, Table 2). In the $\mathrm{ZnO}$ single crystals, the longer wavelengths penetrate deeply into the $\mathrm{ZnO}$, and defects or traps in the semiconductor that act as recombination sites will reduce the minority-carrier collection length. Thus, as the penetration depth increases, so does the chance for recombination in the single crystal. The quantum yield will therefore decrease when the penetration depth is longer than the minority-carrier diffusion length. In contrast, for $\mathrm{ZnO}$ wire arrays, the photogenerated charge-carriers can be collected at the sides of the wires, so although the penetration depth increases as the wavelength decreases, the distance to the junction is relatively constant. Therefore, the charge-collection efficiency should stay essentially the same for all wavelengths, and at longer wavelengths, the wires should generate more current than the single crystal, in accord with the experimental observations.

B. Device Physics Model and J-E Behavior. The device physics model is in agreement with the experimentally observed trends in $V_{\mathrm{oc}}$ and $J_{\mathrm{sc}}$ for the $\mathrm{ZnO}$ nanowires relative to the $\mathrm{ZnO}$ single crystal photoanodes. Simulations of the photoelectrochemical behavior of various $\mathrm{ZnO}$ nanowire structures revealed lower $V_{\text {oc }}$ values than for planar samples, consistent with an increase in junction area and consequently in the dark current density as the junction area increased. The simulated $J_{\mathrm{sc}}$ values for the nanowires were larger than the simulated $J_{\mathrm{sc}}$ values for planar photoelectrodes, despite an identical optical generation rate, mobility, and lifetime throughout both types of simulated structures. Relative to planar $\mathrm{ZnO}$ device structures, these increases in $J_{\mathrm{sc}}$ are consistent with the shorter distance for minority carriers to diffuse before being collected in the nanowires, as well as the larger total volume of semiconductor that contained the electric field of the depletion region in the nanowire arrays.
Simulations of $\mathrm{ZnO}$ nanowires as a function of the wire diameter indicated that $J_{s c}$ would decline significantly at nanowire diameters less than $75 \mathrm{~nm}$, for the specified values of the materials and surface-related parameters. The decline in $J_{\mathrm{sc}}$ is a result of enhanced recombination in the nanowire when the wire core is depleted of majority-carrier electrons. ${ }^{43,49}$ Core depletion, as calculated using the depletion approximation, is expected to occur at $\mathrm{ZnO}$ wire diameters of $<120 \mathrm{~nm}$, given the dopant density and barrier height used in the simulations. However, significant decreases in $J_{\mathrm{sc}}$ were not observed in the simulations until the diameter of the nanowires was $<75 \mathrm{~nm}$. A variation in the simulated bulk charge-carrier lifetime had minimal effect on the value of this threshold diameter for loss of quantum yield for carrier collection. However, modification in the electron recombination velocity produced large $J_{\mathrm{sc}}$ values in small diameter wires (Figure S1, Supporting Information).

C. ZnO Nanowires vs Dye-Sensitized ZnO Photoelectrochemical Systems. For nanowires that are not completely depleted $(d>2 W)$, the space-charge region separates electrons and holes, and therefore lowers the majority-carrier concentration at the surface relative to the majority-carrier concentration in the bulk (i.e., in the core) of the wires. Hence, the minority-carrier transport in such systems is closely related to that of bulk semiconductors in contact with liquids or metals, as opposed to the diffusive charge transport that is thought to occur for nanocrystalline metal oxide particulate networks that are commonly used in dye-sensitized solar cells. The $J-E$ behavior of the $\mathrm{ZnO}$ nanowires observed experimentally in this work is thus consistent with such expectations, because significant rectification was observed for the $\mathrm{ZnO}$ nanowires in contact with the $\mathrm{Fe}(\mathrm{CN})_{6}^{3-/ 4-}$ oneelectron-transfer redox system (Figure 8).

In contrast, nanocrystalline $\mathrm{ZnO}$ and $\mathrm{TiO}_{2}$ photoelectrodes, with or without absorbed dyes, yield no rectification in contact with such one-electron, outer-sphere, redox species, and rectification can only be achieved through kinetically asymmetric redox systems, such as the $\mathrm{I}_{3}^{-} / \mathrm{I}^{-}$redox couple. Hence, the use of nanostructured light absorbers that are not fully depleted allows the observation of large photovoltages and photocurrents in contact with a variety of redox couples, including one-electron redox species, that would not yield satisfactory performance in dye-sensitized solar cell systems. For very small nanoparticles, the carrier transport is diffusive, the depletion layer formation is screened by the electrolyte or otherwise limited by the small thickness of the crystal relative to the expected depletion width in a bulk crystal, and charge separation is achieved by asymmetries in interfacial chargetransfer kinetics based on the interfacial rate constants. In contrast, for light absorbers of size scales similar to the bulk depletion width, the presence of an electric field at or near the surface inherently lowers the concentration of majority carriers, and attracts minority carriers to the semiconductor/liquid interface, facilitating operation in contact with a variety of redox systems and electrolytes, provided a large barrier height is formed.

D. Device Physics Analysis of Different Operational Regimes of Nanostructured Light Absorbers. The experimental observations and simulations described above, in conjunction with the observed high efficiency and internal quantum yield for minority-carrier collection that has been observed for $\mathrm{Si}$ microwires as well as for dye-sensitized nanocrystalline semiconductors, provide an opportunity to formulate a semiquantitative description of the behavior of 
nano/microstructured light absorbers under different operational regimes (Scheme 1). For systems where $d>2 W$,

\section{Scheme 1. Diagram for a Wire System with a Non-Depleted} Core (Left) and a Depleted/Inverted Core (Right) ${ }^{a}$
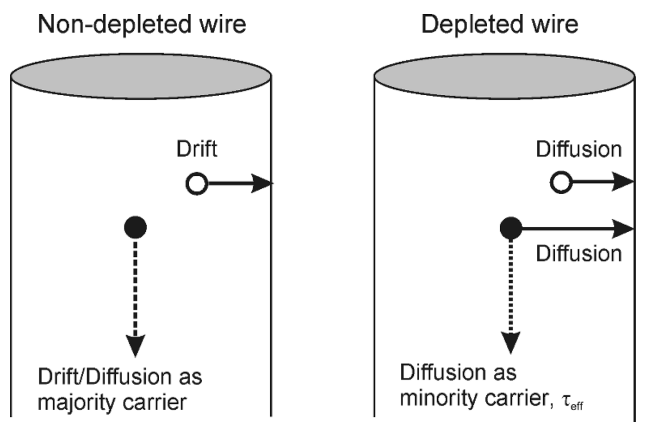

${ }^{a}$ This diagram assumes a contact that forms a high barrier to the ntype wire and favorable electron collection at the base of the wire. In the non-depleted wire, majority-carrier electrons can traverse axially (dashed line) without recombination and surface recombination is prevented by a field, an asymmetric redox couple, and/or an electronically passivated surface. In the depleted wire, electrons must traverse the wire axially effectively as minority carriers (dotted line), requiring a long electron lifetime for high quantum yields. Additionally, the lack of a strong interfacial electric field and the lack of an asymmetric redox couple allows for a high electron density at the interface and will result in high surface recombination velocities as the electrons diffuse to the surface.

orthogonalization of the directions of light absorption and charge-carrier collection results in high quantum yields for minority-carrier collection. The key threshold to be reached is to ensure that the minority-carrier collection length, given by $L_{\text {min }}+W$, where $L_{\min }$ is the minority-carrier diffusion length, exceeds the wire radius, $r .^{50}$ The lifetime of majority carriers is not particularly relevant in this situation, because majority carriers are transported axially, facilitated by a nondepleted core.

When the core of the nanostructure is depleted, i.e., for nanowires in which $d<2 W$, efficient carrier collection, and consequently efficient device operation, can still be obtained but only with proper bulk and interfacial recombination rates (Scheme 1). Under illumination, the axial charge-carrier transport in such systems is primarily diffusive, although drift currents due to weak electric fields are still present. ${ }^{49}$ Under such conditions, selective carrier collection at the contacts, very low effective surface recombination velocities, and long chargecarrier lifetimes are simultaneously required to obtain efficient carrier-collection yields and high photovoltages. The minoritycarrier diffusion length, $L_{\min }$, must be comparable to, or exceed, the length of the wire, $l$, so that photogenerated carriers can diffuse to the bottom contact to be separated and collected. The minority-carrier lifetime in the bulk must thus satisfy the condition that $\tau_{\text {bulk }}>l^{2} / D$, where $D$ is the minority-carrier diffusion coefficient (with $D=k T \mu_{\min }$, where $\mu_{\text {min }}$ is the minority carrier mobility, $T$ is the absolute temperature, and $k$ is Boltzmann's constant) and $l$ is the length of the nanowire. In addition, the surface-based lifetime, $\tau_{\text {surf }}=r / S$ (where $S$ is the surface recombination velocity), of the nanowire must be comparable to, or exceed, the bulk lifetime, $\tau_{\text {bulk. }}$. Hence, in addition to $L_{\min }>l$, efficient device operation requires that a stringent condition on the surface recombination velocity is present:

$$
S<D r / l^{2}
$$

For small diameter, long wires, these two constraints require high purity materials (so that $L_{\min }>l$, just as in a bulk sample), as well as very high interface quality (to produce very low values of $S$ ) and carrier-selective contacts to thereby suppress surface recombination that would otherwise arise from the high junction area of the nanostructured light absorber. For example, for a Si microwire with $l=100 \mu \mathrm{m}$ and $r=1 \mu \mathrm{m}$, efficient carrier collection requires $L_{\min }=100 \mu \mathrm{m}$ as well as $S<\left(10 \mathrm{~cm}^{2}\right.$ $\left.\mathrm{s}^{-1}\right)\left(10^{-4} \mathrm{~cm}\right) /\left(10^{-2} \mathrm{~cm}\right)^{2}=10 \mathrm{~cm} \mathrm{~s}^{-1}$. These surface conditions are attainable for $\mathrm{Si} /$ liquid contacts in contact with kinetically facile, outer-sphere, one-electron redox species that create high barrier heights on $\mathrm{Si}$, such as $1,1^{\prime}$-dimethylferrocene ${ }^{+/ 0}$ in $\mathrm{CH}_{3} \mathrm{OH}^{51}$ For n-type $\mathrm{Fe}_{2} \mathrm{O}_{3}$ nanowires, with $r=$ $10^{-6} \mathrm{~cm}$ and $l=10^{-4} \mathrm{~cm}$, the requirements are that $L_{\min }>10^{-4}$ $\mathrm{cm}$ and $S<\left(1 \mathrm{~cm}^{2} \mathrm{~s}^{-1}\right)\left(10^{-6} \mathrm{~cm}\right) /\left(10^{-4} \mathrm{~cm}\right)^{2}=10^{2} \mathrm{~cm} \mathrm{~s}^{-1}$. Typical values that have been reported for minority-carrier diffusion lengths in n-type $\mathrm{Fe}_{2} \mathrm{O}_{3}$ are $1-5 \mathrm{~nm}$, with $S$ values likely to be $>10^{3} \mathrm{~cm} \mathrm{~s}^{-1}$. For nanocrystalline $\mathrm{TiO}_{2}$ samples, with representative characteristic dimensions of $l=10^{-4} \mathrm{~cm}$ (the thickness of a film), $r=10^{-6} \mathrm{~cm}$ (the diameter of a particle), $D$ $=10^{-1} \mathrm{~cm}^{2} \mathrm{~s}^{-1}$, the constraints are that $L_{\min }>10^{-4} \mathrm{~cm}$ and $S<$ $\left(10^{-1} \mathrm{~cm}^{2} \mathrm{~s}^{-1}\right) \times 10^{-6} \mathrm{~cm} /\left(10^{-4} \mathrm{~cm}\right)^{2}<10^{1} \mathrm{~cm} \mathrm{~s}^{-1}$. These constraints can be met by redox systems such as $\mathrm{I}_{3}^{-} / \mathrm{I}^{-}$, which act as selective contacts to collect holes while impeding the collection of electrons. The semiquantitative analysis provided herein therefore provides a guideline to rapidly assess the materials quality and interface quality that is needed to obtain high solar energy-conversion efficiencies from a variety of nanostructured/microstructured absorber systems, in semiconductor/liquid junctions as well as solid-state contact configurations.

\section{CONCLUSIONS}

The photoelectrochemical properties of solution-grown $\mathrm{ZnO}$ nanowire arrays are similar to those of bulk single crystalline $\mathrm{ZnO}$. Values for short-circuit current densities and for the long wavelength external quantum yields were larger in wire-array samples than for planar samples, due to short distances for minority-carrier collection in the nanowires. The open-circuit potentials under illumination were more positive for wire array samples $\left(E_{\mathrm{oc}}=-390 \mathrm{mV}\right.$ vs SCE $)$ than for single crystals $\left(E_{\mathrm{oc}}=\right.$ $-605 \mathrm{mV}$ vs SCE). A device physics model was consistent with the observed experimental behavior of the $\mathrm{ZnO}$ wire arrays. A regime under which completely depleted wires can function with high quantum yields for carrier collection was identified, and the device physics treatment of such a system was related to the behavior of systems in which the carrier transport is predominantly diffusive. The wire arrays used herein were not completely depleted, as evidenced by the large internal quantum yield values measured for the $\mathrm{ZnO} /$ liquid contacts evaluated in this work.

\section{ASSOCIATED CONTENT}

\section{S Supporting Information}

Details of the simulation parameters, additional simulation results, and full ref 2 . This material is available free of charge via the Internet at http://pubs.acs.org.

\section{AUTHOR INFORMATION}

\section{Notes}

The authors declare no competing financial interest. 


\section{ACKNOWLEDGMENTS}

This work was supported by the Department of Energy, Office of Basic Energy Sciences, DE-FG02-07ER46405. N.C.S. acknowledges the NSF for an American Competitiveness in Chemistry postdoctoral fellowship (CHE-1042006).

\section{REFERENCES}

(1) Putnam, M. C.; Boettcher, S. W.; Kelzenberg, M. D.; TurnerEvans, D. B.; Spurgeon, J. M.; Warren, E. L.; Briggs, R. M.; Lewis, N. S.; Atwater, H. A. Energy Environ. Sci. 2010, 3, 1037-1041.

(2) Boettcher, S. W.; Warren, E. L.; Putnam, M. C.; Santori, E. A.; Turner-Evans, D.; Kelzenberg, M. D.; Walter, M. G.; McKone, J. R; Brunschwig, B. S.; Atwater, H. A.; et al. J. Am. Chem. Soc. 2011, 133, 1216-1219.

(3) Brunner, K. Rep. Prog. Phys. 2002, 65, 27-72.

(4) Chen, C. C.; Chao, C. Y.; Lang, Z. H. Chem. Mater. 2000, 12, $1516-1518$

(5) Chen, M.; Xie, Y.; Lu, J.; Xiong, Y. J.; Zhang, S. Y.; Qian, Y. T.; Liu, X. M. J. Mater. Chem. 2002, 12, 748-753.

(6) Duan, X. F.; Wang, J. F.; Lieber, C. M. Appl. Phys. Lett. 2000, 76, 1116.

(7) Gong, D.; Grimes, C. A.; Varghese, O. K.; Hu, W. C.; Singh, R. S.; Chen, Z.; Dickey, E. C. J. Mater. Res. 2001, 16, 3331-3334.

(8) Greene, L. E.; Law, M.; Tan, D. H.; Montano, M.; Goldberger, J.; Somorjai, G.; Yang, P. D. Nano Lett. 2005, 5, 1231-1236.

(9) Grimes, C. A. J. Mater. Chem. 2007, 17, 1451-1457.

(10) Gudiksen, M. S.; Wang, J. F.; Lieber, C. M. J. Phys. Chem. B 2002, 106, 4036-4039.

(11) Kan, S. H.; Aharoni, A.; Mokari, T.; Banin, U. Faraday Discuss. 2004, 125, 23-38.

(12) Krishnamachari, U.; Borgstrom, M.; Ohlsson, B. J.; Panev, N.; Samuelson, L.; Seifert, W.; Larsson, M. W.; Wallenberg, L. R. Appl. Phys. Lett. 2004, 85, 2077.

(13) Law, M.; Goldberger, J.; Yang, P. D. Annu. Rev. Mater. Res. 2004, $34,83-122$.

(14) Li, Q.; Gong, X. G.; Wang, C. R.; Wang, J.; Ip, K.; Hark, S. Adv. Mater. 2004, 16, 1436-1440.

(15) Li, Y. C.; Li, X. H.; Yang, C. H.; Li, Y. F. J. Phys. Chem. B 2004, 108, 16002-16011.

(16) Lian, S. Y.; Kang, Z. H.; Wang, E. B.; Jiang, M.; Hu, C. W.; Xu, L. Solid State Commun. 2003, 127, 605-608.

(17) Lin, H. M.; Chen, Y. L.; Yang, J.; Liu, Y. C.; Yin, K. M.; Kai, J. J.; Chen, F. R.; Chen, L. C.; Chen, Y. F.; Chen, C. C. Nano Lett. 2003, 3, 537-541.

(18) Mokari, T.; Banin, U. Chem. Mater. 2003, 15, 3955-3960.

(19) Nedeljkovic, J. M.; Micic, O. I.; Ahrenkiel, S. P.; Miedaner, A.; Nozik, A. J. J. Am. Chem. Soc. 2004, 126, 2632-2639.

(20) Qian, G. X.; Huo, K. F.; Fu, J. J.; Hung, T. F.; Chu, P. K. J. Appl. Phys. 2008, 104, 014312.

(21) Sun, Y.; Fuge, G. M.; Ashfold, M. N. R. Chem. Phys. Lett. 2004, $396,21-26$.

(22) Tian, Z. R. R.; Voigt, J. A.; Liu, J.; McKenzie, B.; McDermott, M. J.; Rodriguez, M. A.; Konishi, H.; Xu, H. F. Nat. Mater. 2003, 2, 821826.

(23) Vayssieres, L. Adv. Mater. 2003, 15, 464-466.

(24) Vayssieres, L.; Keis, K.; Hagfeldt, A.; Lindquist, S. E. Chem. Mater. 2001, 13, 4395-4398.

(25) Verheijen, M. A.; Immink, G.; de Smet, T.; Borgstrom, M. T.; Bakkers, E. J. Am. Chem. Soc. 2006, 128, 1353-1359.

(26) Xiang, B.; Zhang, H. Z.; Li, G. H.; Yang, F. H.; Su, F. H.; Wang, R. M.; Xu, J.; Lu, G. W.; Sun, X. C.; Zhao, Q.; Yu, D. P. Appl. Phys. Lett. 2003, 82, 3330.

(27) Kayes, B. M.; Filler, M. A.; Putnam, M. C.; Kelzenberg, M. D.; Lewis, N. S.; Atwater, H. A. Appl. Phys. Lett. 2007, 91, 103110.

(28) Toh, C. S.; Kayes, B. M.; Nemanick, E. J.; Lewis, N. S. Nano Lett. 2004, 4, 767-770.

(29) Cesar, I.; Kay, A.; Martinez, J. A. G.; Gratzel, M. J. Am. Chem. Soc. 2006, 128, 4582-4583.
(30) Khan, S. U. M.; Akikusa, J. J. Phys. Chem. B 1999, 103, 71847189.

(31) Maeda, K.; Takata, T.; Hara, M.; Saito, N.; Inoue, Y.; Kobayashi, H.; Domen, K. J. Am. Chem. Soc. 2005, 127, 8286-8287.

(32) Park, J.-H.; Kim, S.; Bard, A. J. Nano Lett. 2006, 6, 24-28.

(33) Mor, G. K.; Shankar, K.; Paulose, M.; Varghese, O. K.; Grimes, C. A. Nano Lett. 2005, 5, 191-195.

(34) Ahn, K.-S.; Shet, S.; Deutsch, T.; Jiang, C.-S.; Yan, Y.; Al-Jassim, M.; Turner, J. J. Power Sources 2008, 176, 387-392.

(35) Vayssieres, L.; Manthiram, A. J. Phys. Chem. B 2003, 107, 26232625.

(36) Vayssieres, L.; Sathe, C.; Butorin, S. M.; Shuh, D. K.; Nordgren, J.; Guo, J. H. Adv. Mater. 2005, 17, 2320-2323.

(37) Li, Q. C.; Kumar, V.; Li, Y.; Zhang, H. T.; Marks, T. J.; Chang, R. P. H. Chem. Mater. 2005, 17, 1001-1006.

(38) Li, Q. H.; Wan, Q.; Liang, Y. X.; Wang, T. H. Appl. Phys. Lett. 2004, 84, 4556.

(39) Yi, G. C.; Wang, C. R.; Park, W. I. Semicond. Sci. Technol. 2005, 20, S22-S34.

(40) Dittrich, T.; Kieven, D.; Rusu, M.; Belaidi, A.; Tornow, J.; Schwarzburg, K.; Lux-Steiner, M. Appl. Phys. Lett. 2008, 93, 053113.

(41) Law, M.; Greene, L. E.; Johnson, J. C.; Saykally, R.; Yang, P. D. Nat. Mater. 2005, 4, 455-459.

(42) Peiro, A. M.; Ravirajan, P.; Govender, K.; Boyle, D. S.; O’Brien, P.; Bradley, D. D. C.; Nelson, J.; Durrant, J. R. J. Mater. Chem. 2006, 16, 2088-2096.

(43) Hagedorn, K.; Forgacs, C.; Collins, S.; Maldonado, S. J. Phys. Chem. C 2010, 114, 12010-12017.

(44) Tian, B.; Zheng, X.; Kempa, T. J.; Fang, Y.; Yu, N.; Yu, G.; Huang, J.; Lieber, C. M. Nature 2007, 449, 885-889.

(45) Spurgeon, J. M.; Atwater, H. A.; Lewis, N. S. J. Phys. Chem. C 2008, 112, 6186-6193.

(46) Hamann, T. W.; Gstrein, F.; Brunschwig, B. S.; Lewis, N. S. J. Am. Chem. Soc. 2005, 127, 7815-7824.

(47) Webb, L. J.; Lewis, N. S. J. Phys. Chem. B 2003, 107, 54045412.

(48) Bansal, A.; Li, X. L.; Yi, S. I.; Weinberg, W. H.; Lewis, N. S. J. Phys. Chem. B 2001, 105, 10266-10277.

(49) Kelzenberg, M. D. Silicon Microwire Photovoltaics. California Institute of Technology, 2010.

(50) Kayes, B. M.; Atwater, H. A.; Lewis, N. S. J. Appl. Phys. 2005, 97, 114302.

(51) Rosenbluth, M. L.; Lieber, C. M.; Lewis, N. S. Appl. Phys. Lett. 1984, 45, 423-425. 